\title{
Technical note: Feeding zilpaterol hydrochloride to calf-fed Holstein steers improves muscle conformation of top loin steaks
}

\author{
T.E. Lawrence a,*, D.M. Allen ${ }^{\text {b }}$, R.J. Delmore ${ }^{c}$, J.L. Beckett ${ }^{\mathrm{d}}$, W.T. Nichols ${ }^{\mathrm{e}}$, M.N. Streeter ${ }^{\mathrm{e}}$, \\ D.A. Yates ${ }^{\mathrm{e}}$, J.P. Hutcheson ${ }^{\mathrm{e}}$ \\ a Department of Agricultural Sciences, West Texas A E M University, Canyon, TX, 79016, USA \\ b Private Consultant, Derby, KS, 67037, USA \\ c Department of Animal Science, California Polytechnic State University, San Luis Obispo, CA, 93407, USA \\ d Beckett Consulting Services, Atascadero, CA, 93422, USA \\ e Intervet Schering Plough Animal Health, DeSoto, KS, 66018, USA
}

\begin{abstract}
The objective of this research was to evaluate changes in the muscle conformation of subprimal top-loins ( $M$. longissimus lumborum) from calf-fed Holstein steers fed zilpaterol hydrochloride ( $\mathrm{ZH})$. Top-loins $(\mathrm{n}=100)$ were transversely cut into $2.54 \mathrm{~cm}$-thick steaks, weighed, and objectively evaluated via image analysis software for muscle area, width, and length traits. Top-loin steaks from steers fed ZH were heavier $(P<0.01$; $367 \mathrm{vs} .337 \mathrm{~g})$ and average muscle area per steak was greater $\left(P<0.05 ; 80.9 \mathrm{vs} .77 .2 \mathrm{~cm}^{2}\right)$ as compared to steaks from control steers. Muscle width (medial-lateral) was not different $(P=0.23)$ between control steers and those fed ZH. However, steaks from steers fed ZH had greater $(P<0.05)$ depth (dorsal-ventral) than steaks from control steers throughout the top-loin. The increased muscle depth of top-loins from calf-fed Holstein steers fed ZH may improve the center-of-the-plate salability of a cut that has traditionally suffered from poor muscling.
\end{abstract}

\section{Introduction}

Current growth enhancement technologies include feed additives that allow meat animal producers to improve the efficiency of production through increased rates of protein accretion. One of the newest technologies available is zilpaterol hydrochloride $(\mathrm{ZH})$, a $\beta_{2^{-}}$ adrenergic agonist. Studies on the use of $\mathrm{ZH}$ have demonstrated its effectiveness as a growth promoter of cattle (Avendaño-Reyes et al., 2006; Elam et al., 2009; Vasconcelos et al., 2008; Scramlin et al., 2010; Strydom, Frylinck, Montgomery \& Smith, 2009). These data have illustrated that ZH has particular effectiveness in increasing the size of the longissimus muscle. Other research investigating the effects of cimaterol (Chikhou et al., 1993), clenbuterol (Ricks, Dalrymple, Baker, \& Ingle, 1984), and L-644,969 (Moloney, Allen, Ross, Olson, \& Convey, 1990 ) fed to ruminants has also demonstrated an increase in $M$. longissimus area (LMA). However, none of these reports indicate if this increase in muscle area growth is medial-lateral or dorsal-ventral growth. Additionally, previous research did not quantify the change in muscle shape throughout the anterior-posterior length of the muscle.

Holstein steers supply approximately $8 \%$ of the U.S. fed beef market (Garcia et al., 2008). Foodservice purveyors in the U.S. often avoid calf-fed Holstein (Holstein calves fed a nutrient dense ration in confinement from $\sim 150 \mathrm{~d}$ of age until harvest at a mature weight) cuts for center-of-the-plate items due to the poor muscle conformation of these cuts (Lundeen, 2008). The increase in LMA that accompanies ZH feeding could be a very positive trait for the calf-fed Holstein industry. The objective of this research was to quantify the change in $M$. longissimus lumborum (LL) muscle shape in response to feeding $\mathrm{ZH}$.

\section{Materials and methods}

Animal Care and Use Committee approval was not obtained for this study because the samples were obtained from federally inspected slaughter facilities. The live animal experiment from which these samples were obtained was approved by the California Polytechnic State University Institutional Animal Care and Use Committee as indicated in Beckett et al. (2009).

\subsection{Carcass selection and loin processing}

Calf-fed Holstein beef carcasses ( $n=100 ; 50$ per treatment) from steers fed $\mathrm{ZH}$ ( $8.3 \mathrm{mg} / \mathrm{kg}$ DM basis) for 0 or $20 \mathrm{~d}$, as described in experiment 1 of Beckett et al. (2009) were randomly pre-selected within the mean hot carcass weight $(\mathrm{HCW}) \pm 1$ SD within each treatment; $394.4 \pm 30.2$ and $406.0 \pm 33.2 \mathrm{~kg}$ for 0 and $20 \mathrm{~d}$ treatments, respectively. Carcasses were chilled $\left(0^{\circ} \mathrm{C}\right)$ for $24 \mathrm{~h}$ after 
harvest, then carcass yield parameters (12th rib subcutaneous fat thickness, percentage kidney-pelvic-heart fat, LMA, $\mathrm{LMA}^{-\mathrm{HCW}}$ ) were evaluated for each carcass. Calculated yield grades (YG) were determined from the USDA YG (USDA, 1997) regression equation.

The left side LL (IMPS $180 A, 2 \times 3,0.64 \mathrm{~cm}$ trim; USDA, 1996) was removed from each carcass during fabrication, vacuum packaged at the commercial processor and transported $(1592 \mathrm{~km})$ under refrigeration $\left(-1.1^{\circ} \mathrm{C}\right)$ via commercial trailer to the West Texas A\&M University Meat Laboratory.

Upon arrival at West Texas A\&M University, LL primals were aged for $7 \mathrm{~d}$ at $1.1{ }^{\circ} \mathrm{C}$, then transversely sliced into 2.54 -cm-thick steaks (IMPS 1180; USDA, 1996). Quantity of steaks per LL ranged from 12 to 18. Untrimmed steaks were weighed to the nearest $0.1 \mathrm{~g}$ (Sartorius model EA6DCE-1, Göttingen, Germany). The anterior surface of each steak was scanned (Hewlett Packard 4470C, Palo Alto, CA); subsequent images were saved as JPEG files and objectively evaluated using Assess (American Phytopathological Society Press, St. Paul, MN) image analysis software. Image evaluations included: 1) total muscle area, $\mathrm{cm}^{2} ; 2$ ) maximum medial-lateral width of $\mathrm{LL}, \mathrm{cm} ; 3$ ) maximum dorsal-ventral depth of LL at $25 \%$ length of LL from the midline, $\mathrm{cm} ; 4$ ) maximum dorsal-ventral depth of LL at $50 \%$ length of LL from the midline, $\mathrm{cm}$; 5) maximum dorsal-ventral depth of LL at 75\% length of LL from the midline, $\mathrm{cm}$; 6) area of LL muscle, $\mathrm{cm}^{2}$; and 7) area of $M$. gluteus medius (GM) when present, $\mathrm{cm}^{2}$ (Fig. 1).

\subsection{Experimental design and statistical analysis}

A one-way treatment structure ( $0 \mathrm{~d}$ or $20 \mathrm{~d}$ ZH feeding) was used in a completely randomized design structure with an individual loin from a carcass being the experimental unit. Carcass yield parameter data were analyzed using the MIXED procedure of SAS (SAS Institute, 2003). The statistical model included the fixed effect of treatment. Repeated measures data (total muscle area, LL length, LL width, portion weights) were analyzed using a compound symmetry covariance model. The statistical model included the fixed effect of treatment and random effect of HCW. Treatment means were generated using the LSMEANS option.

\section{Results and discussion}

Carcasses selected for this study did not differ $(P>0.05)$ in terms of yield parameters (HCW, 12th rib fat depth, or $\mathrm{LMA}^{-\mathrm{HCW}}$ ) as a result of $\mathrm{ZH}$ feeding (Table 1). Lack of difference in HCW is unusual in cattle fed ZH for $20 \mathrm{~d}$ and this is likely an artifact of the sample size of this group as the overall HCW means of these treatments were different (Beckett et al., 2009). Absolute difference in HCW between cattle fed $\mathrm{ZH}$ for 0 or $20 \mathrm{~d}$ as reported in Beckett et al. (2009) was $11.6 \mathrm{~kg}$, which was numerically similar to the $11.5 \mathrm{~kg}$ difference found in the smaller sampling used in the current study. The inability to detect a difference in HCW was due to the much larger SEM ( $4.27 \mathrm{~kg}$ ) in the current study than the $2.6 \mathrm{~kg}$ reported by Beckett et al. (2009). Although HCW was not different between the $0 \mathrm{~d}$ and $20 \mathrm{~d}$ sample carcasses, LMA of calf-fed Holstein steers was $5.5 \mathrm{~cm}^{2}$ greater $(P=0.0013 ; 6.8 \%$ increase) for those fed $\mathrm{ZH}$ for $20 \mathrm{~d}$. These data are comparable to previous data of Avendaño-Reyes et al. (2006), Elam et al. (2009), and Vasconcelos et al. (2008) whom reported increased LMA of $12.7 \%, 9.1 \%$, and $10.2 \%$, respectively, concomitant with ZH feeding for $20 \mathrm{~d}$. Additionally, the calculated USDA yield grade of carcasses from steers fed ZH for $20 \mathrm{~d}$ was 0.29 units lower ( $P=0.0149 ; 8.9 \%$ decrease). These data are also similar to data from Elam et al. (2009), and Vasconcelos et al. (2008) whom reported decreased USDA calculated yield grades of $11.1 \%$ and $14.1 \%$, respectively upon feeding $\mathrm{ZH}$ for $20 \mathrm{~d}$.

No difference $(P=0.21)$ in the average number of steaks yielded per loin was detected between $\mathrm{ZH}$ treatments (Table 2). However, $\mathrm{ZH}$ carcasses yielded a greater $(P=0.007)$ weight of steaks per kg of HCW as compared to steers not fed ZH. Muscle conformation analysis indicated that average total muscle area (inclusive of LL and GM muscles) of toploin steaks was $3.7 \mathrm{~cm}^{2}$ greater $(P=0.004 ; 4.8 \%$ increase) for top-loins

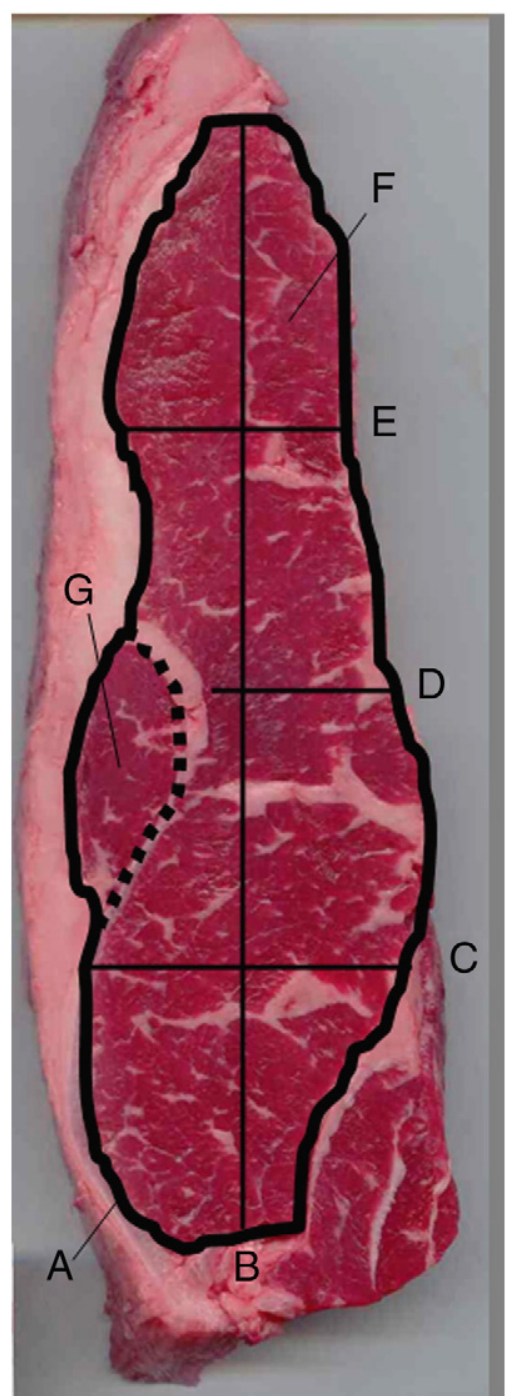

Fig. 1. Muscle conformation evaluations of M. Longissimus lumborum from calf-fed Holstein steers A) total muscle area, $\mathrm{cm}^{2}$; B) maximum medial-lateral width of $\mathrm{LL}, \mathrm{cm} ; \mathrm{C}$ ) maximum dorsal-ventral depth of lean at $25 \%$ width of LL from the midline, $\mathrm{cm}$; D) maximum dorsalventral depth of lean at $50 \%$ width of LL from the midline, $\mathrm{cm}$; E) maximum dorsal-ventral depth of lean at $75 \%$ width of LL from the midline, $\mathrm{cm}$; F) area of $\mathrm{LL}, \mathrm{cm}^{2}$; and G) area of GM when present, $\mathrm{cm}^{2}$.

Table 1

Least squares means ${ }^{a}$ and descriptive statistics of carcass yield parameters from calffed Holstein steers fed zilpaterol hydrochloride for 0 or $20 \mathrm{~d}$ prior to harvest and sampled for top-loin conformation evaluation.

\begin{tabular}{lccc}
\hline Item & $\begin{array}{l}\text { Zilpaterol hydrochloride } \\
\text { treatment }\end{array}$ & Mean & SE \\
\hline Hot carcass weight, $\mathrm{kg}$ & $0 \mathrm{~d}$ & 393.7 & 4.27 \\
& $20 \mathrm{~d}$ & 405.2 & \\
12th rib subcutaneous fat depth, cm & $0 \mathrm{~d}$ & 0.87 & 0.05 \\
& $20 \mathrm{~d}$ & 0.80 & \\
M. longissimus area, $\mathrm{cm}^{2}$ & $0 \mathrm{~d}$ & $81.4^{\mathrm{y}}$ & 1.17 \\
& $20 \mathrm{~d}$ & $86.9^{\mathrm{z}}$ & \\
M. longissimus area, $\mathrm{cm}^{2}$ per 100 kg & $0 \mathrm{~d}$ & 20.7 & 0.28 \\
hot carcass weight $^{\text {Calculated USDA yield grade }}{ }^{\mathrm{b}}$ & $20 \mathrm{~d}$ & 21.5 & \\
& $0 \mathrm{~d}$ & $3.25^{\mathrm{z}}$ & 0.08 \\
\hline
\end{tabular}

Within a composition indicator, means with different superscripts differ $(P<.05)$.

b USDA yield grade $=2.5+(2.5 \times 12$ th rib subcutaneous fat thickness, inches $)$ $+(0.0038 \times$ hot carcass weight, pounds $)+(0.2 \times$ percentage kidney-pelvic-heart fat $)$ $-\left(0.32 \times\right.$ longissimus muscle area, inches $\left.{ }^{2}\right)$. Lower calculated yield grade values estimate more salable product; higher calculated yield grade values estimate less salable product. 
Table 2

Least squares means ${ }^{a}$ and descriptive statistics of top-loin muscle conformation parameters from calf-fed Holstein steers fed zilpaterol hydrochloride for 0 or $20 \mathrm{~d}$ prior to harvest.

\begin{tabular}{|c|c|c|c|}
\hline Item & $\begin{array}{l}\text { Zilpaterol } \\
\text { hydrochloride } \\
\text { treatment }\end{array}$ & Mean & SEM \\
\hline \multirow[t]{2}{*}{ Average number of steaks per top-loin } & $0 \mathrm{~d}$ & 14.8 & 0.14 \\
\hline & $20 \mathrm{~d}$ & 14.6 & \\
\hline \multirow[t]{2}{*}{ Steak yield/hot carcass weight, $\mathrm{g} / \mathrm{kg}$} & $0 \mathrm{~d}$ & $12.7^{\mathrm{y}}$ & 0.13 \\
\hline & $20 \mathrm{~d}$ & $13.2^{z}$ & \\
\hline \multirow[t]{2}{*}{ Total muscle area ${ }^{\mathrm{b}}, \mathrm{cm}^{2}$} & $0 \mathrm{~d}$ & $77.2^{\mathrm{y}}$ & 0.88 \\
\hline & $20 \mathrm{~d}$ & $80.9^{z}$ & \\
\hline \multirow[t]{2}{*}{ M. Longissimus lumborum width ${ }^{\mathrm{c}}, \mathrm{cm}$} & $0 \mathrm{~d}$ & 16.7 & 0.12 \\
\hline & $20 \mathrm{~d}$ & 16.9 & \\
\hline \multirow[t]{2}{*}{ M. Longissimus lumborum depth $25 \%{ }^{\mathrm{d}}$, cm } & $0 \mathrm{~d}$ & $5.3^{\mathrm{y}}$ & 0.07 \\
\hline & $20 \mathrm{~d}$ & $5.7^{\mathrm{z}}$ & \\
\hline \multirow[t]{2}{*}{ M. Longissimus lumborum depth $50 \%{ }^{\mathrm{e}}, \mathrm{cm}$} & $0 \mathrm{~d}$ & $5.5^{\mathrm{y}}$ & 0.06 \\
\hline & $20 \mathrm{~d}$ & $5.7^{z}$ & \\
\hline \multirow[t]{2}{*}{ M. Longissimus lumborum depth $75 \%{ }^{\mathrm{f}}, \mathrm{cm}$} & $0 \mathrm{~d}$ & 4.7 & 0.06 \\
\hline & $20 \mathrm{~d}$ & 4.8 & \\
\hline \multirow[t]{2}{*}{ M. longissimus area, $\mathrm{cm}^{2}$} & $0 \mathrm{~d}$ & 65.8 & 1.14 \\
\hline & $20 \mathrm{~d}$ & 68.6 & \\
\hline \multirow[t]{2}{*}{ M. gluteus medius area, $\mathrm{cm}^{2}$} & $0 \mathrm{~d}$ & 16.9 & 1.20 \\
\hline & $20 \mathrm{~d}$ & 18.6 & \\
\hline \multirow[t]{2}{*}{ Portion size, g } & $0 \mathrm{~d}$ & $337^{y}$ & 4.20 \\
\hline & $20 \mathrm{~d}$ & $367^{z}$ & \\
\hline \multirow[t]{2}{*}{ Vein steaks ${ }^{g}, \%$} & $0 \mathrm{~d}$ & 20.1 & - \\
\hline & $20 \mathrm{~d}$ & 19.4 & - \\
\hline
\end{tabular}

a Within a muscle conformation parameter, means with different superscripts differ $(P<.05)$.

b Total muscle area includes both longissimus lumborum and gluteus medius muscles.

c Width of M. longissimus lumborum (lateral-medial) within steaks.

d Depth of $M$. longissimus lumborum (dorsal-ventral) at $25 \%$ of the width of the $M$. longissimus lumborum from the midline.

e Depth of M. longissimus lumborum (dorsal-ventral) at $50 \%$ of the width of the $M$. longissimus lumborum from the midline.

${ }^{f}$ Depth of $M$. longissimus lumborum (dorsal-ventral) at $75 \%$ of the width of the $M$. longissimus lumborum from the midline.

$\mathrm{g}$ Percentage of top-loin steaks with gluteus medius muscle present.

from calf-fed Holstein steers fed ZH for $20 \mathrm{~d}$ as compared to non-ZH calffed Holsteins. However, no difference was detected in independent LMA $(P=0.08)$ or $\mathrm{GM}$ area $(P=0.30)$. No difference $(P=0.07)$ was detected in medial-lateral LL width. However, dorsal-ventral LL depth was greater at $25 \%$ and $50 \%$ of the length of the LL from the midline; $0.4 \mathrm{~cm}$ $(P=0.0002 ; 7.5 \%$ increase $)$ and $0.2 \mathrm{~cm}(P=0.02 ; 3.6 \%$ increase $)$, respectively (Table 2; Fig. 2). These data illustrate the improvement in LMA concomitant with ZH feeding is largely the result of increase in dorsal-ventral muscle depth. This growth led to increased portion sizes $(P<0.0001 ; 367$ vs. $337 \mathrm{~g} ; 8.9 \%$ increase $)$ of steaks from steers fed $\mathrm{ZH}$. The percentage of top-loin steaks containing both LL and GM, known in the industry as vein-steaks, was not different between $\mathrm{ZH}$ and non-ZH calf-fed Holstein steers (Table 2).

\section{Conclusion}

These findings suggest that an increase in LMA and depth will result from the feeding of $\mathrm{ZH}$ which should result in a greater percentage of usable steak yield from top loins from $\mathrm{ZH}$ fed calf-fed Holstein steers. Feeding $\mathrm{ZH}$ should increase the value of top loin subprimals, thus improving their carcass values in relation to beef steer carcasses and could potentially help calf-fed Holstein steers capture a greater portion of the center-of-the-plate market.

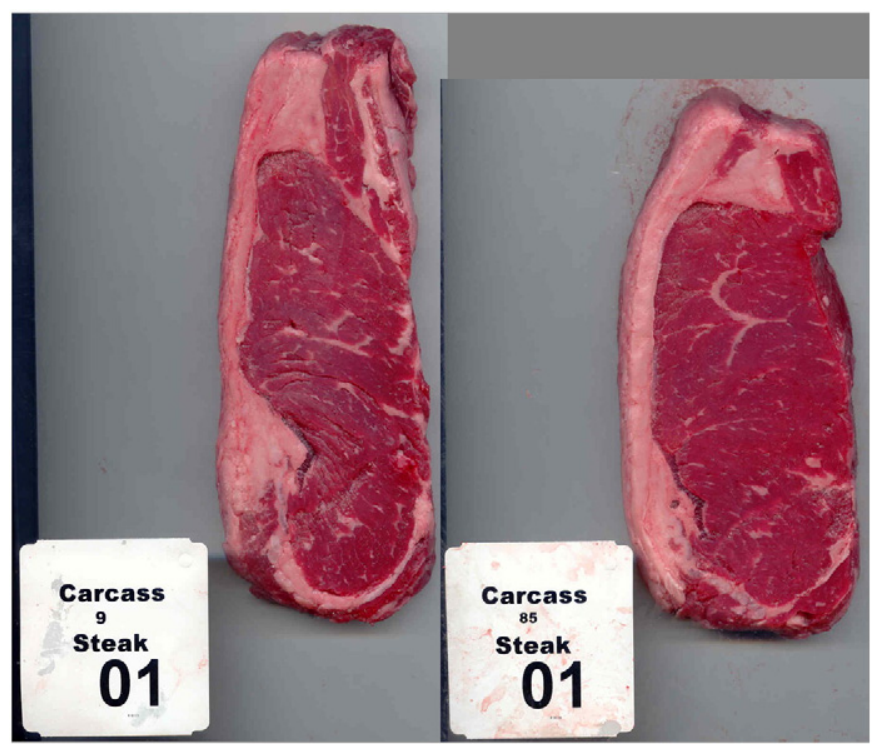

Fig. 2. Typical anterior-most steaks from top-loins (M. Longissimus lumborum) of calffed Holstein steers fed zilpaterol hydrochloride for 0d (left) and $20 \mathrm{~d}$ (right). These images represent mean $\mathrm{LMA}^{-\mathrm{HCW}}$ values for each treatment. The identification tags are $66.675 \times 69.85 \mathrm{~mm}$. Note the narrow and angular shaped steak on the left as compared to the increased muscle depth illustrated in the steak shown at the right.

\section{References}

Avendaño-Reyes, L., Torres-Rodríguez, V., Meraz-Murillo, F. J., Pérez-Linares, C., Figueroa-Saavedra, F., \& Robinson, P. H. (2006). Effects of two ß-adrenergic agonists on finishing performance, carcass characteristics, and meat quality of feedlot steers. Journal of Animal Science, 84, 3259-3265.

Beckett, J. L., Delmore, R. J., Duff, G. C., Yates, D. A., Allen, D. M., Lawrence, T. E., et al. (2009). Effects of zilpaterol hydrochloride on growth rates, feed conversion, and carcass traits in calf-fed Holstein steers. Journal of Animal Science, 87, 4092-4100.

Chikhou, F. H., Moloney, A. P., Allen, P., Joseph, R. L., Tarrant, P. V., Quirke, J. F., et al. (1993). Long-term effects of cimaterol in Friesian steers: II. Carcass composition and meat quality. Journal of Animal Science, 71, 914-922.

Elam, N. A., Vasconcelos, J. T., Hilton, G., VanOverbeke, D. L., Lawrence, T. E., Montgomery, T. H., et al. (2009). Effect of zilpaterol hydrochloride duration of feeding on performance and carcass characteristics of feedlot cattle. Journal of Animal Science, 87, 2133-2141.

Garcia, L. G., Nicholson, K. L., Hoffman, T. W., Lawrence, T. E., Hale, D. S., Griffin, D. B., et al. (2008). National Beef Quality Audit-2005: survey of targeted cattle and carcass characteristics related to quality, quantity, and value of fed steers and heifers. Journal of Animal Science, 86, 3533-3543.

Lundeen, T. (2008, December 15). Technology enhances beef eating experience. Feedstuffs (pp. 10-11).

Moloney, A. P., Allen, P., Ross, D. B., Olson, G., \& Convey, E. M. (1990). Growth, feed efficiency and carcass composition of finishing Friesian steers fed the $\beta$-adrenergic agonist L-644, 969. Journal of Animal Science, 68, 1269-1277.

Ricks, C. A., Dalrymple, R. H., Baker, P. K., \& Ingle, D. L. (1984). Use of a $\beta$-agonist to alter fat and muscle deposition in steers. Journal of Animal Science, 59, 1247-1255.

SAS Institute (2003). SAS/STAT user's guide (version 9.2). Cary, NC: SAS Institute, Inc..

Scramlin, S. M., Platter, W. J., Gomez, R. A., Choat, W. T., McKeith, F. K., \& Killefer, J. (2010). Comparative effects of ractopamine hydrochloride and zilpaterol hydrochloride on growth performance, carcass traits, and longissimus tenderness of finishing steers. Journal of Animal Science, 88, 1823-1829.

Strydom, P. E., Frylinck, L., Montgomery, J. L., \& Smith, M. F. (2009). The comparison of three $\beta$-agonists for growth performance, carcass characteristics and meat quality of feedlot cattle. Meat Science, 81, 557-564.

USDA (1996). Institutional Meat Purchase Specifications For Fresh Beef Products. Washington, DC: Agricultural Marketing Service, USDA.

USDA (1997). Official United States Standards for Grades of Carcass beef. : Unites States Department of Agriculture, Agricultural Marketing Service, Livestock \& Seed Division.

Vasconcelos, J. T., Rathmann, R. J., Reuter, R. R., Leibovich, J., McMeniman, J. P., Hales, K. E., et al. (2008). Effects of duration of zilpaterol hydrochloride feeding and days on the finishing diet on feedlot cattle performance and carcass traits. Journal of Animal Science, 86, 2005-2015. 